\title{
PENGGUNAAN EKSTRAKSI SEKUENSIAL UNTUK SPESIASI LOGAM BERAT DI SEDIMEN
}

\author{
Oleh \\ Lestari $^{1)}$
}

\section{ABSTRAK}

THE USE OF SEQUENTIAL EXTRACTION PROCEDURES FOR HEAVY METAL SPECIATION IN SEDIMENT. Metals accumulation in sediments from both natural and anthropogenic sources occurs in the same way, making it difficult to identify and determine the origin of heavy metals present in the sediments. Moreover, the total concentration of metals often does not accurately represent their characteristics and toxicity. In order to overcome the mentioned obstacles, it is necessary to evaluate the individual fractions of the metals to fully understand their actual and potential environmental effects. Single extraction is thus used generally to provide a rapid evaluation of the exchangeable metal fraction in sediments. However, complicated sequential extraction procedures are used to provide more detailed information regarding different metal phase associations.

\section{PENDAHULUAN}

Logam berat merupakan salah satu polutan lingkunganyang patut diwaspadai, karena memiliki toksisitas yang tinggi, melimpah serta mudah terakumulasi pada berbagai macam organisme (Riba et al., 2004). Peningkatan urbanisasi dan industrialisasi juga menjadi kontributor dalam meningkatkan total jumlah beban polutan yang dibuang. Buangan tersebut kemungkinan mengandung logam berat (Fatoki \& Mathabata, 2001).

Konsentrasi logam berat dalam sedimen dapat ditelusuri hingga konsentrasi yang terdapat dalam organisme hidup, seperti fitoplankton, zooplankton, ikan bahkan hingga manusia, sehingga dampaknya dapat membahayakan kesehatan masyarakat.
Logam bioavailable dalam sedimen dapat memengaruhi distribusi dan komposisi organisme bentik, dan dapat pula menyebabkan peningkatan konsentrasi polutan dalam organisme hidup (Caplat et al., 2005; Kress et al., 2004). Logam berat dengan konsentrasi yang tinggi pada organisme hidup dapat menyebabkan terjadinya kelainan morfologis, gangguan neurofisiologis, perubahan genetik sel (mutasi), tetatogenesis dan karsinogenesis. Selain itu, logam berat dapat memegaruhi enzimatik dan aktivitas hormonal, serta tingkat pertumbuhan dan peningkatan angka kematian (Bubb et al., 1991). Logam berat yang terakumulasi dalam sedimen dapat berasal dari sumber alami maupun antropogenik. Sedimen dapat berperan sebagai agen pengambil

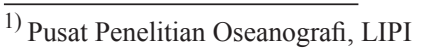


(scavenger agent), sekaligus tempat penyerapan logam berat di lingkungan perairan. Dengan demikian, sedimen dapat digunakan sebagai salah satu indikator pencemaran logam berat (Sakai et al.,1986).

Akumulasi logam dalam sedimen baik yang berasal dari sumber alami maupun antropogenik terjadi dengan cara yang sama, antara lain melalui pelapukan batuan, erosi tanah atau pelarutan garam mineral yang larut dalam air, sehingga sulit untuk mengidentifikasi dan menentukan asal logam berat yang ada di sedimen (Idris et al., 2007). Selain itu, konsentrasi total logam seringkali tidak akurat mewakili karakteristik dan toksisitasnya. Asumsi mengenai penggunaan total konsentrasi logam sebagai kriteria untuk menilai efek potensial dari sedimen terkontaminasi yang menyiratkan bahwa semua bentuk logam tertentu, memiliki dampak yang sama terhadap lingkungan tidak dapat dipertahankan (Tessier et al., 1979)

Solusi untuk mengatasi hal tersebut, adalah perlu melakukan evaluasi fraksi individu dari tiap logam, dan upaya ini sangat membantu dalam memahami efek lingkungan aktual dan potensial logam tersebut (Tessier et al., 1979). Ekstraksi tunggal umumnya digunakan untuk memberikan evaluasi yang cepat terhadap fraksi logam yang dapat dipertukarkan pada tanah dan sedimen (Quevauviller et al., 2002; Sahuquillo et al., 2003). Namun demikian, berbagai prosedur ekstraksi sekuensial dapat digunakan untuk memberikan informasi yang lebih rinci mengenai asosiasi fase logam yang berbeda (Tessier et al., 1979; Templeton et al., 2001). Tulisan ini bertujuan untuk mengetahui penggunaan prosedur ekstraksi sekuensial dalam menentukan spesiasi logam berat dalam sedimen.

Berbagai teknik dengan berbagai pereaksi ekstraksi dan kondisi percobaan telah banyak digunakan. Teknik tersebut menggunakan ekstraksi dengan cara lima langkah (Tessier et al.,1979), yakni ekstraksi dengan cara empat langkah (BCR, Bureau Commune de Reference of the European Commission), dan cara ekstraksi 6 langkah (Kersten \& Forstner, 1986), yang kemudian metode tersebut dikenal dengan metode ekstraksi sekuensial (Cuong \& Obbard, 2006). Beberapa metode analisis yang telah digunakan untuk penentuan kandungan logam berat di lingkungan laut antara lain dengan Flame AAS (Gomez-Ariza et al., 1999), Atomic Fluorescence Spectrometry, Anodic Stripping Voltametry, ICP-AES, dan ICP-MS.

Mobilitas dan ketersediaan secara biologi (bioavailable) logam berat, sangat bergantung pada bentuk kimia dan mineralogi tempat terjadinya (Baeyens et al., 2003). Beberapa studi spesiasi telah dilakukan untuk menentukan bentuk logam berat, namun bukan kandungan logam totalnya. Studi ini dapat mengungkapkan tingkat bioavailabilitas logam pada sedimen pelabuhan, dan juga dapat mengonfirmasi bahwa sedimen adalah bioindikator pencemaran logam berat di lingkungan laut (Riba et al., 2004; Idris et al., 2007; Esslemont, 2000). 


\section{LOGAM BERAT SEBAGAI PENCEMAR LAUT}

Unsur-unsur mayor dan minor (major and trace element) terjadi secara alami di lingkungan (Esslemont, 2000). Secara alami, ukuran partikel logam pada sedimen yang terkontaminasi dapat mempersulit penilaian sedimen, karena jumlah logam terukur tidak dapat menggambarkan secara langsung pengayaan antropogenik (Esslemont, 2000). Selain secara alami, aktivitas lain seperti kegiatan pelabuhan, industri, emisi kendaraan, pertanian dan limbah rumah tangga, juga dapat bertindak sebagai sumber pencemaran logam berat di lingkungan laut (Idris et al., 2007).

Dampak buruk yang dapat terjadi akibat pencemaran lingkungan logam berat diantaranya adalah penyerapan dalam rantai makanan oleh organisme. Distribusi dan asosiasi logam pada sedimen dapat terjadi dengan berbagai cara, yakni meliputi pertukaran ion, adsorpsi, presipitasi dan kompleksasi. Secara umum, logam berat merupakan kontaminan pada lingkungan sedimen yang stabil dan persisten. Logam seperti $\mathrm{Zn}, \mathrm{Cu}, \mathrm{Fe}$, dan $\mathrm{Mn}$ diperlukan untuk aktivitas metabolik pada organisme bergantung pada nilai gizi dan toksisitasnya. Logam seperti $\mathrm{Cd}, \mathrm{Hg}$, $\mathrm{Cr}, \mathrm{Pb}$ dan As menunjukkan toksisitas yang ekstrim, walaupun ditemukan pada konsentrasi yang rendah. Dengan demikian, hal ini membuat pemantauan lingkungan perairan penting, dan perlu dilakukan secara reguler.

\section{LOGAM BERAT DI SEDIMEN LAUT}

Sedimen dapat menjadi sumber utama dari kontaminan, yang dampaknya dapat menimbulkan risiko terhadap kehidupan akuatik (Williamson et al.,1996). Akumulasi logam berat pada sedimen disebabkan oleh sifat lingkungan laut yang sangat dinamis, yang memungkinkan asimilasi cepat dari polutan ini ke dalam sedimen melalui proses oksidasi, degradasi, dispersi, pengenceran dan arus laut (Oroko et al., 2012). Sebuah studi tentang spesiasi logam pada sedimen laut di pesisir Singapura memastikan bahwa sedimen merupakan tempat penyimpanan utama dan sumber logam berat di lingkungan laut serta memainkan peran penting dalam pengangkutan dan penyimpanan logam berbahaya (Bruder et al., 2002).

Ketersediaan logam berat dalam organisme laut dapat ditelusuri dari karakteristik sedimen seperti $\mathrm{pH}$, kandungan dan jenis bahan organik, serta kelembaban (Iwegbue et al., 2006). Proses geokimia dan fisiologis keduanya penting untuk menentukan ketersediaan logam (Gambar 1). Setelah dibuang ke lingkungan perairan, logam dipecah antara fase padat dan cair. Dalam setiap fase, pembagian atau spesiasi lebih lanjut terjadi di antara ligan spesifik, ditentukan oleh konsentrasi ligan dan frekuensi masing-masing asosiasi ligan logam. Dengan demikian, organisme tidak pernah terpapar logam sebagai satu kesatuan. Dalam setiap fase, organisme dapat terpapar berbagai bentuk fisikokimia masing-masing logam, dan setiap bentuknya mungkin berbeda aksesibilitasnya terhadap organisme. 


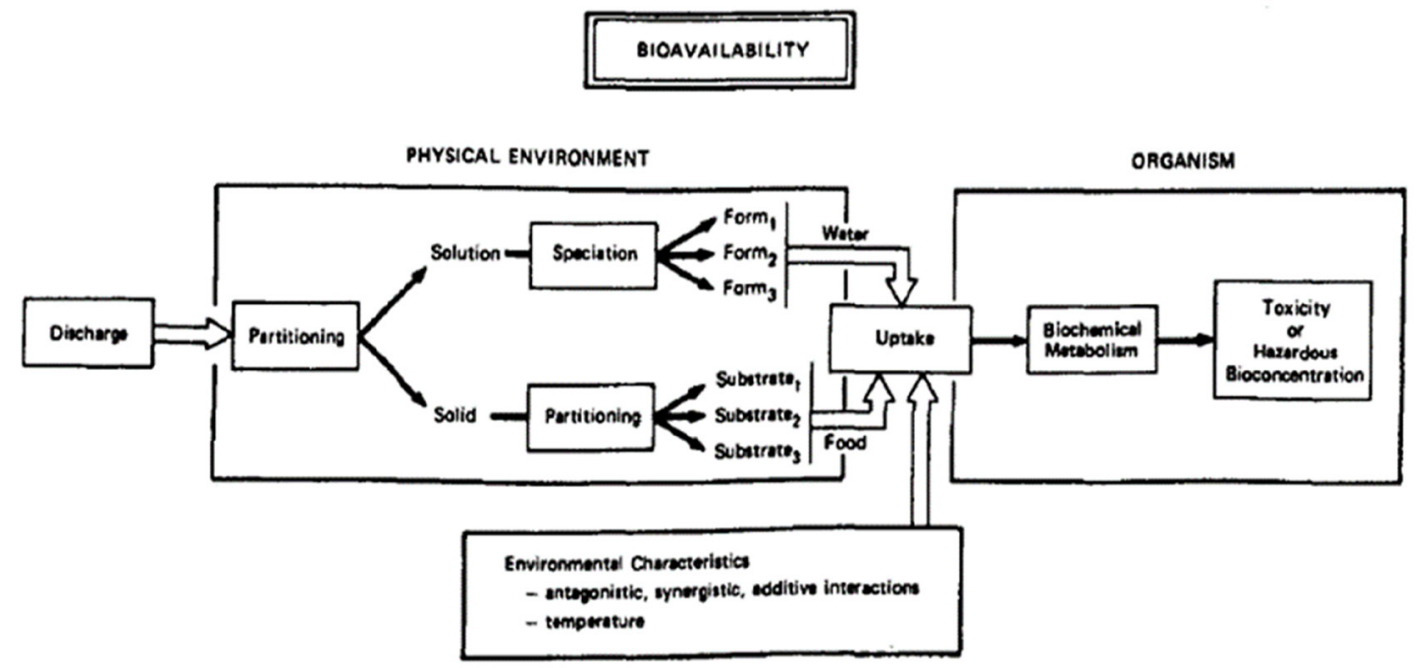

Gambar 1. Proses yang memengaruhi ketersediaan biologi logam terkait sedimen sebelum, selama dan setelah pengambilan (Luoma, 1983)

Faktor-faktor yang mempengaruhi ketersediaan biologi logam (Campbel et al., 1988) yaitu:

1. Spesies logam dan ketersediaan biologis,

2. Serapan oleh organisme (serapan pada tingkat organisme, tingkat selular dan penyerapan oleh mekanisme),

3. Faktor-faktor yang mempengaruhi pengambilan logam oleh organisme yaitu suhu, salinitas, konsentrasi ion hidogen, kondisiredoks, kompleksasi, melalui usus, interaksi logam-logam, metilasi dan demetilasi, serta efek bentuk makanan pada serapan logam.

\section{PENGARUH FISIKOKIMIA TERHADAP MOBILITAS LOGAM BERAT DALAM SEDIMEN}

Logam berat merupakan salah satu kontaminan yang umumnya terikat pada sedimen. Ketersediaan secara biologi dan toksisitas logam ini terhadap organisme akuatik bergantung pada bentuk fisik dan kimia logam, serta beberapa parameter fisikokimia seperti suhu, $\mathrm{pH}$, salinitas, oksigen terlarut dan komposisi bahan partikulat. Dalam air tawar, $\mathrm{pH}$ merupakan faktor pengendali sedangkan salinitas merupakan salah satu faktor yang memengaruhi pemisahan kontaminan antara sedimen dan air di sedimen pada lingkungan laut atau muara karena besarnya variabilitas parameter ini di dalamnya (Chapman \&Wang, 2001).

Guevara-Riba et al. (2005) melakukan penelitian tentang pengaruh $\mathrm{pH}$, dan salinitas pada toksisitas logam berat dalam sedimen terhadap estuarin yang tenang. Penelitian tersebut menunjukkan bahwa logam berat cenderung lebih tersedia secara biologi pada salinitas rendah daripada salinitas tinggi, dan ini memberi kemungkinan lebih beracun bagi organisme yang terpapar. Hal ini berarti bahwa efek salinitas bervariasi pada tiap logam, 
tergantung pada proses desorpsi dari sedimen ke air atau koagulasi, flokulasi dan pengendapan. Oleh karena itu, sedimen di daerah yang terkontaminasi logam berat kronis, akan cenderung lebih efisien menjebak $\mathrm{Zn}$, $\mathrm{Cu}$ dan $\mathrm{Pb}$ pada nilai salinitas rendah. Hal ini berkaitan dengan fakta bahwa $\mathrm{Cd}$ cenderung lebih mudah berpindah (mobile) karena salinitas meningkat.

\section{METODE ANALISIS}

Akumulasi logam pada sedimen sulit untuk diidentifikasi dan ditentukan asal-usul logam beratnya (Idris et al., 2007). Sejak awal tahun 1980 dan 1990an, metode ekstraksi sekuensial telah dikembangkan untuk menentukan spesiasi logam dalam sedimen (Tessier et al., 1979, Cotzee, 1993), karena konsentrasi logam secara keseluruhan tidak secara akurat mewakili karakteristik dan toksisitasnya. Untuk mengatasi hambatan yang disebutkan di atas, maka sangat penting untuk mengevaluasi fraksi individu logam untuk sepenuhnya memahami efek lingkungan aktual dan potensial mereka (Tessier et al.,1979).

Sampai saat ini, digesi dengan menggunakan asam kuat sering digunakan untuk penentuan logam berat total dalam sedimen. Namun, metode ini dapat menyesatkan karena berpotensi overestimasi risiko paparan saat menilai efek lingkungan. Berbagai prosedur ekstraksi berurutan telah dikembangkan, mulai dari tiga sampai enam langkah: tiga langkah (Ure et al.,1993; Kiratli \& Ergin, 1996), lima langkah (Tessier et al., 1979) sampai enam langkah (Kersten \& Forstner, 1986) dalam proses ekstraksinya.

Prosedur ekstraksi berurutan (SEP) merupakan metode untuk menilai mobilitas logam berat pada sedimen (Riba et al., 2003; Stephens et al., 2001; Svete et al., 2001), tanah (Mossop \& Davidson, 2003) dan bahan limbah (Bruder et al., 2002; Alvarez et al., 2002). Selain itu sequencing extraction technique (SEP) juga dapat memberikan informasi mengenai identifikasi ikatan yang ada pada sedimen, dan seberapa besar ikatan antara logam dan partikulat lainnya (Luoma \& Rainbow, 2008).

Di antara berbagai teknik yang ada dan dengan menggunakan berbagai pereaksi ekstraksi, serta kondisi eksperimental metode ekstraksi lima langkah (Tessier et al.,1979), dan metode ekstraksi enam langkah (Kersten \& Forstner, 1986) merupakan metode yang banyak digunakan untuk mengetahui distribusi logam berat pada sedimen dan tanah. Berdasarkan dua skema ini, beberapa prosedur kemudian dimodifikasi pada urutan pereaksi atau kondisi eksperimental (Gomez-Ariza et al., 2000). Mengingat berbagai keragaman prosedur dan kurangnya keseragaman, maka protokol BCR diusulkan untuk menyelaraskan skema ekstraksi untuk analisis sedimen (Ure etal., 1993). Metode ini telah divalidasi dengan menggunakan bahan referensi bersertifikasi sedimen BCR-701 dengan konsentrasi $\mathrm{Cd}, \mathrm{Cr}$, $\mathrm{Cu}, \mathrm{Ni}, \mathrm{Pb}$ dan $\mathrm{Zn}$ yang telah diketahui nilainya. Metode ini dapat diterapkan dan 
diterima (Salomons, 1993; Fiedler et al., 1994; Ho \& Evans, 1997; Lopez-Sanchez et al.,1998; Usero et al., 1998), meskipun ada beberapa kekurangan dalam tahap ekstraksi berurutan (Tu et al., 1994). Berbagai modifikasi dari metode ini telah dilakukan oleh beberapa peneliti (Yuan et al., 2004; Cuong \& Obbard, 2006).

\section{MODIFIKASI METODE BCR \\ - THREE STEP SEQUENTIAL EXTRACTION PROCEDURE (SEP)}

Berdasarkan Sarkar et al., (2014), ada empat fase ikatan yang di analisis dengan metode BCR. Keempat fase tersebut adalah sebagai berikut ;

1. Fase Acid-soluble merupakan fase yang memiliki ikatan yang paling labil, apabila berikatan dengan sedimen maupun tanah, sehingga fase ini berbahaya dan mudah terlarut dalam air apabila $\mathrm{pH}$ mengalami penurunan.

2. Fase Reducible merupakan fase yang berikatan dengan besi dan mangan, dan mudah terlepas dari sedimen apabila terdapat perubahan dari kondisi oksik menjadi anoksik. Perubahan kondisi ini disebabkan adanya aktivitas mikroorganisme dalam tanah maupun sedimen.

3. Fase Oxidisable merupakan fase yang menunjukkan jumlah logam berat yang berikatan dengan bahan organik dan sulfida yang mana ikatan ini dapat lepas dibawah kondisi oksidasi.

4. Fase residual merupakan fase yang bersifat Non-bioavailable.

Salah satu modifikasi yaitu penggunaan aqua regia pada fase residual yang dilakukan dalam prosedur ekstraksi sekuensial ini dapat dilihat pada Tabel 1.

Tabel 1. Tahapan ekstraksi utama untuk prosedur ekstraksi sekuensial BCR yang di modifikasi.

\begin{tabular}{llll}
\hline Step & Sediment phase & Extractant & Shaking time and Temperature \\
\hline F1 & Water and acid soluble, & $40 \mathrm{ml}$ of $0.11 \mathrm{~mol}$ & $16 \mathrm{~h}$ at room temperature at \\
& and exchangeable & $\mathrm{L}^{-1} \mathrm{CH}_{3} \mathrm{COOH}$ & $22 \pm 5^{\circ} \mathrm{C}$ and speed $30 \pm 10 \mathrm{rpm}$. \\
& (acid-soluble fraction - & & The extract was separated \\
& bound to carbonates) & & from the solid phase by \\
& & centrifugation at 3000 rpm for \\
& & 20 min.
\end{tabular}

F2 Reducible (iron / manganese oxyhydroxides) (reducible fraction bound to Fe and $\mathrm{Mn}$ oxides)
$40 \mathrm{ml}$ of $0.5 \mathrm{~mol} \mathrm{~L}^{-1} \quad 16 \mathrm{~h}$ at room temperature $\mathrm{HONH}_{2} \cdot \mathrm{HCl}(\mathrm{pH}$ $22 \pm 5^{\circ} \mathrm{C}$ and speed $30 \pm 10 \mathrm{rpm}$. The extract was separated from the solid phase by centrifugation at $3000 \mathrm{rpm}$ for $20 \mathrm{~min}$. 
F3 Oxidizable (organic matter and sulfides
$10 \mathrm{ml}$ of $8.8 \mathrm{~mol} \mathrm{~L}^{-1} \quad 1 \mathrm{~h}$ at room temperature

$\mathrm{H}_{2} \mathrm{O}_{2}$ (two times), $1 \mathrm{~h}$ at $85^{\circ} \mathrm{C}$ cool and add $50 \quad 1 \mathrm{~h}$ at $85^{\circ} \mathrm{c}$

$\mathrm{mL}$ of $1 \mathrm{~mol} \mathrm{~L}^{-1} \quad 16 \mathrm{~h}$ at room temperature

$\mathrm{NH}_{4} \mathrm{OAc}(\mathrm{pH} 2) \quad 22 \pm 5^{\circ} \mathrm{C}$ and speed $30 \pm 10 \mathrm{rpm}$.

The extract was separated from the solid phase by centrifugation at $3000 \mathrm{rpm}$ for 20 min.

$10 \mathrm{~mL}$ of aqua regia Digesting in a mixture aqua regia in Microwave digestion

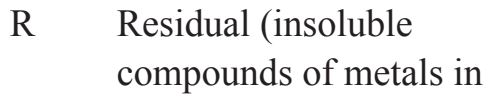

the steps before)

(residual fraction -

strongly associated to

the crystalline structures

of minerals)

\section{AKURASI METODE UNTUK METODE SEP BCR YANG DI MODIFIKASI}

Cara untuk mengetahui apakah modifikasi metode BCR ini dapat diterima atau tidak untuk analisis sedimen, maka diperlukan uji akurasi metode. Uji akurasi metode juga dimaksudkan untuk memastikan ketepatan dan ketelitian dalam proses analisis tersebut. Uji ini dilakukan dengan menggunakan Certified Raw Material (CRM) PACS 2.

Nilai yang diperhitungkan adalah nilai recovery setiap sampel sedimen PACS 2. Dimana perhitungan recovery adalah sebagai berikut (Cuong \& Obbard, 2006)

$\%$ Recovery $=\frac{\text { Konsentrasi logam berat Cu yang didapatkan }}{\text { Konsentrasi logam berat yang seharusnya }} \times 100$

Untuk nilai recovery dalam analisis fraksinasi logam berat $\mathrm{Cu}$ dalam sedimen yaitu sebagai berikut :
$\%$ Recovery $=\frac{\mathrm{F} 1+\mathrm{F} 2+\mathrm{F} 3+\mathrm{F} 4}{\text { Konsentrasi logam berat Cu yang seharusnya }} \times 100$

Sebagai contoh perhitungan nilai recovery PACS 2 adalah sebagai berikut;

$$
93.6 \%=\frac{35.24+89.03+137.27+17.66}{298} \times 100
$$

Penentuan apakah suatu metode sudah dikatakan benar atau baik digunakan, dapat dilihat dari akurasi yang diperoleh. Akurasi suatu metode dikatakan sangat baik apabila nilai recovery yang didapat, yaitu $100 \%$. Adapun rumus akurasi untuk mendapatkan nilai recovery adalah sebagai berikut.

Keterangan :

$\mathrm{X}=$ rerata hasil pengujian

$\mathrm{U}=$ nilai benar atau nilai acuan CRM.

Akurasi metode dilakukan dengan menggunakan tiga sampel Certified Raw Material (CRM) PACS-2, dengan berat tiap sampel $1 \mathrm{~g}$. Nilai recovery yang 
didapat untuk analisis konsentrasi dan analisis fraksinasi logam berat $\mathrm{Cu}$ dalam sedimen disajikan pada Tabel 2 dan Tabel 3 (Lestari, 2017).

Tabel 2. Nilai recovery total $\mathrm{Cu}$ dengan metode CEM Microwave

\begin{tabular}{|c|c|c|c|}
\hline NO & ID CRM & Nilai recovery & Standar CRM PACS 2 (Cu) \\
\hline 1 & PACS 2A & $92.4 \%$ & \multirow{2}{*}{$310 \pm 12$} \\
\hline 2 & PACS 2B & $93.3 \%$ & \\
\hline 3 & PACS 2C & $96.3 \%$ & \\
\hline
\end{tabular}

Tabel 3. Nilai Recovery metode SEP BCR yang dimodifikasi

\begin{tabular}{|c|c|c|c|}
\hline NO & ID CRM & Nilai recovery & Standar CRM PACS 2 (Cu) \\
\hline 1 & PACS 2A & $93 \%$. & \multirow{2}{*}{$310 \pm 12$} \\
\hline 2 & PACS 2B & $92 \%$ & \\
\hline 3 & PACS 2C & $86 \%$. & \\
\hline
\end{tabular}

Nilai recovery ketiga sampel tersebut dengan dua metode memiliki kisaran persentase, yaitu $94 \%$ dan $90 \%$. Menurut Voica et al.(2012), nilai recovery yang dibutuhkan untuk menentukan apakah suatu metode tersebut aman digunakan adalah sebesar 90\%. Dengan demikian kedua metode tersebut sudah baik dan benar.

\section{PENUTUP}

Akumulasi logam pada sedimen sulit untuk diidentifikasi dan ditentukan asal-usul logam beratnya karena konsentrasi logam secara keseluruhan tidak secara akurat mewakili karakteristik dan toksisitasnya. Untuk mengatasi hambatan yang disebutkan di atas, maka sangat penting untuk mengevaluasi fraksi individu logam untuk sepenuhnya memahami efek lingkungan aktual dan potensial mereka. Prosedur ekstraksi sekuensial BCR yang telah sedikit dimodifikasi dapat digunakan untuk mengetahui spesiasi logam dalam sedimen dan mengevaluasi potensi mobilitas dan kemungkinan pemindahan logam berat dari sedimen ke lingkungan sekitarnya. Spesiasi logam akan menentukan ketersediaan biologi logam terhadap organisme dan dapat digunakan untuk mengkaji resiko logam berat di lingkungan.

\section{DAFTAR PUSTAKA}

Alvarez E. A., M. C. Mochón., J. C Jiménez Sánchez., and M. Rodríguez. 2002. Heavy metal extractable forms in sludge from wastewater treatment plants. Chemosphere 47: 765775 .

Baeyens W., F. Monteny, M. Leermakers, and S. Bouillon. 2003. Evaluation of sequential extraction on dry and wet sediments. Anal. Bioanal. Chem 376: 890-901. 
Bruder-Hubscher V., F. Lagarde, M. J. F. Leroy, C. Conghanowr, and F. Engelhard. 2002. Application of a sequential extraction procedure to study the release of elements from municipal solid waste incineration bottom ash. Anal. Chim. Acta. 451: 285-295.

Bubb J. M., and J. N. Lester. 1991. The impact of heavy metals on lowland rivers and the implications for man and the environment. Sci. Total Environ. 100 Spec No: 207-233.

Campbell P. G. C, A. G Lewis, P. M Chapman, A. A. Crowder, W. K. Fletcher, B. Imber, S. N. Luoma, P. M. Stokes, and M. Winfrey. 1988. Biologically available metals in sediments, National Research council of Canada, Publication No. NRCC 27694

Caplat C., H. Texier, D. Barillier, and C. Lelievre. 2005. Heavy metals mobility in harbour contaminated sediments: the case of Port-en-Bessin. Mar. Pollut. Bull. 50: 504-511.

Chapman P. M., dan F. Wang. 2001. Assessing sediment contamination in estuaries. Environ. Toxicol. Chem. 20: 3-22.

Coetzee P. P. 1993. Determination and speciation of heavy metals in sediments of the Hartebeespoort Dam by sequential extraction. Water SA 19: 291-300.
Cuong T. D., and J. P Obbard. 2006. Metal speciation in coastal marine sediments from Singapore from Singapore using a modified BCR-sequential extraction procedure. Appl. Geochemistry 21: 1335-1346.

Esslemont G. 2000. Heavy metals in seawater, marine sediments and corals from the Townsville section, Great Barrier Reef Marine Park, Queensland. Marine Chemistry 71: 215231.

Fatoki O. S., and S. Mathabata. 2001. An assessment of heavy metals pollution in the East London and Port Elizabeth harbours. Water S A 27: 233-240.

Fiedler H. D., J. F. Lopez-Sanchez, R. Rubio, G. Rauret, and P. H. Quevauviller. 1994. Study of the stability of extractable trace metal contents in a river sediment using Sequential extraction. Analyst 119: 11091114.

Gomez-Ariza J. L., I. Giraldez, D. E. Sanchez- Rodas, and E. Morales. 2000. Metal sequential extraction procedure optimized for heavy metal polluted and iron- oxide rich sediments. Anal. Chim. Acta. 414: 151164.

Guevara-Riba A., A. Sahuquillo, R. Rubio, and G. Rauret. 2005. Effect of chloride on heavy 
metal mobility of harbour sediments. Anal. Bioanal. Chem. 382: 353-359.

Ho D. M., and G. J. Evans. 1997. Operational speciation of cadmium, copper, lead and zinc in the NIST standard reference materials 2710 and 2711 (Montana soil) by the BCR sequential extraction procedure and flame atomic absorption spectrometry. Analytical Сотти. 34: 363-364.

Idris A. M., M. A. H. Eltayeb, S. S. Potgieter-Vermaak, R. Grieken, and J. H. Potgieter. 2007. Assessment of heavy metal pollution in Sudanese harbours along the Red Sea coast. Microchemical. J 87: 104-112.

Iwegbue C. M. A., F. E. K. Egobueze, and K. Opuene. 2006. Preliminary assessment of heavy metals levels of soils of an oil field in the Niger Delta. Int. J. Sci. Technol. 3: 167-172.

Kersten M., and U. Frostner. 1986. Chemical fractionation of heavy metals in anoxic estuarine and coastal sediments. Water. Sci. Technol. 18: 121-130.

Kiratli N., and M. Ergin. 1996. Partitioning of heavy metals in surface Black Sea sediments. Applied Geochemistry 11: 775788.
Kress N., B. Herut, and B. S. Galil. 2004. Sewage sludge impact on sediment quality and benthic assemblages off the Mediterranean coast of Israel-a long-term study. Mar. Environ. Res. 57: 213-233.

Lopez- Sanchez J. F., A. Sahuquillo, H. D. Fiedler, R. Rubio, and G. Rauret.1998. CRM 601, A stable material for its extractable content of heavy metals. Analyst 123: 16751677.

Luoma S. N. 1983. Bioavailability of trace metals to aquatic organisms-A review: The Science of the Total Environment. 28: 1-22.

Mossop K. F., and C. M. Davidson. 2003. Comparison of original and modified BCR sequential extraction procedures for the fractionation of copper, iron, lead, manganese and zinc in soil and sediments. Anal. Chim. Acta. 478: 111-118.

Okoro H. K, O. S. Fatoki, F. A. Adekola, B. J. Ximba, and R. G. Snyman. 2012. A review of sequential extraction procedures for heavy metals speciation in soil and sediments. 1: 181. doi:10.4172/ scientificreports. 181

Quevauviller P., and J. Olazabal. 2002. Links between the water framework directive, the thematic strategy soil protection and research trends with focus 
on pollution issues. $J$. of soil and sed. 3: 243-244.

Riba I., E. García-Luque, J. Blasco, and T. A. Del Valls. 2003. Bioavailability of heavy metals bound to estuarine sediments as a function of $\mathrm{pH}$ and salinity values. Chemical Speciation and Bioavailability 15: 101114.

Sahuquillo A., A. Rigol, and G. Rauret. 2003. Overview of the use of leaching, extraction tests for risk assessment of trace metals in contaminated soils and sediments. Trend Analytical Chemistry 22: 152-159.

Sakai H., Y. Kojima, and K. Saito. 1986 Distribution of heavy metals in water and sieved sediment in the Toyoher River. Water Res. 20: 559-567.

Sarkar, S. K., P. J. C. Favas., D. Rakshit., and K. K. Satpathy. 2014. Geochemical speciation and risk assessment of heavy metals in soils and sediments. environmental risk assessment of soil contamination. Chapter 25. http://www.intechopen. com/. Diakses tanggal 2 Juni 2016

Salomons W. 1993. Adoption of common schemes for single and sequential extractions of trace metals in soil and sediments. Int. J. Environ. Anal. Chem. 51: 3-4.
Stephens S. R., B. J. Alloway, A. Parker, J. E. Carter, and M. E Hodson. 2001 Changes in the leachability of metals from dredged canal sediments during drying and oxidation. Environ. Pollut. 114: 407-413.

Svete P., R. Milacic, and B. Pihlar. 2001. Partitioning of $\mathrm{Zn}, \mathrm{Pb}$ and $\mathrm{Cd}$ in river sediments from a lead and zinc mining area using the BCR three-step sequential extraction procedure. J. Environ. Monit. 3: 586-590.

Templeton D. M., F. Ariese, and R. Cornels. 2001 IUPAC guidelines for terms related to chemical Speciation and fractionation of elements. Pure. Appl. Chem. 72: 1453-1470.

Tessier A., P. G. C. Campbel, and M. Bisson. 1979. Sequential extraction procedure for the speciation of particulate trace metals. Anal. Chem. 51: 844851.

Tu Q., X. Z. Shan, and Z. Ni. 1994. Evaluation of a sequential extraction procedure for the fractionatio of amorphous iron and manganese oxides and organic matter in soils. The Sci. of The total Environ. 151: 159165.

Ure A. M., V. Quevauviller, H. Muntau, and B. Griepink. 1993. Speciation of heavy metals in solids and harmonization 
of extraction techniques undertaken under the auspices of the BCR of the Commission of the European Communities. Int. J. of Environ. Anal. Chem. 51: 135.

Usero J., M. Gamero, J. Morrillo, and I. Gracia. 1998. Comparative study of the sequential extraction procedures for metals in marine sediments. Environ. Int. 24: 487-496.

Voica C., M. H. Kovacs, A. Dehelean, D. Ristoiu, \& A. Iordache. 2012. ICP-MS determinations of heavy metals in surface waters from Transylvania. Romanian Journal of Physics 57(6-7): 1184-1193.
Williamson R., L. F. Van Dam, M. O. Bell Grenn, J. P. Kim, and F. A. Arcadi. 1996. Heavy metal and suspended sediments fluxes from a contaminated intertidal inlet (Manukau Harbour, New Zealand). Mar. Pollut. Bull. 32: 812-822.

Yuan C. G., J. B. Shi, B. He, J. F. Liu, and L. N. Liang. 2004. Speciation of heavy metals in marine sediments from the East China Sea by ICP-MS with sequential extraction. Environ. Int 30: 769-783. 